Journal of Environmental
AnSN: $2525-815 \mathrm{X}$

\title{
Cálculo da evolução temporal de área degradada às margens do rio Tapacurá na Zona da Mata de Pernambuco, Brasil
}

\section{Calculation of temporal evolution of degraded area on the banks of the Tapacurá River in the Zona da Mata de Pernambuco, Brazil}

Emmanuelle Maria Gonçalves Lorena ${ }^{a}$, Ana Paula Xavier de Gondra Bezerra ${ }^{a}$, Ítala Gabriela Sobral dos Santos ${ }^{\mathrm{a}}$, Raimundo Mainar de Medeiros ${ }^{\mathrm{a}}$, Fernando Cartaxo Rolim Neto ${ }^{\mathrm{a}}$, Romildo Morant de Holanda $^{\mathrm{a}}$

${ }^{a}$ Universidade Federal Rural de Pernambuco-UFRPE, Departamento de Tecnologia Rural, Rua Manuel de Medeiros, s/n, Dois Irmãos, Recife-PE, Brasil. CEP: 52171-900. E-mail: emmanuelle@ lorenas.com.br, anapaula.gondra@ gmail.com, italagsobral@hotmail.com, romildomorant@gmail.com.

\section{A R T I C L E I N F O}

Recebido 16 Jan 2018

AceitoDiaMêsAno

PublicadoDiaMêsAno

\begin{abstract}
A B S T R A C T
Currently, in the municipality of Vitória de Santo Antão in Pernambuco, there is economic growth due to investments in the industrial area, with an increase in the urban population and a decrease in the rural population. The combination of actions that impact the environment on the reduction of natural resources with negative anthropogenic impacts generates environmental degradation. In many cases, it occurs due to the lack of human concern with the survival of future generations due to the current needs of urban infrastructure. The objective of this study was to identify the environmental degradation by anthropic actions in an urban area on the banks of the Tapacurá River in the city of Vitória de Santo Antão, Brazil, using data geoprocessing techniques in a defined area. With the aid of Google Earth Pro, vegetated areas were analyzed on maps in July 2006, June 2011 and November 2015. The studied area was considered degraded after local visual evaluation, through irregular constructions, occurring the incidence of landfill with residues of construction and incorrect disposition of solid residues, which caused damage to vegetation especially in the riparian forests along the banks of the river, with results of vegetal area in decreasing evolution in years 2006, 2011 and 2015, respectively, of $61.65 \% 40.30 \%$ and $13.49 \%$, totaling $86.51 \%$ of degradation, which impairs water flow during periods of high rainfall, generating impermeable layers in valleys areas, which causes vulnerability to areas under flood risk.
\end{abstract}

Keywords: Geoprocessing, absence of vegetation, vulnerability.

\section{R E S U M O}

Atualmente, no município de Vitória de Santo Antão em Pernambuco, ocorre um crescimento econômico por causa dos investimentos na área industrial, com elevação da população urbana e decréscimo da população rural. A combinação de ações impactantes para o meio ambiente quanto a redução dos recursos naturais em função da ação de impactos antrópicos negativos, gerando a degradação ambiental, em muitos casos, ocorre devido a despreocupação humana com a sobrevivência das futuras gerações por conta das necessidades atuais de infraestrutura urbana. $\mathrm{O}$ objetivo deste estudou consistiu na identificação da degradação ambiental por ações antrópicas em área urbana as margens do rio Tapacurá no município de Vitória de Santo Antão-PE, utilizando técnicas de geoprocessamento de dados em área delimitada. Com o auxílio do Google Earth Pro foram analisadas as áreas vegetadas nos mapas nos meses de julho de 2006, junho de 2011 e novembro de 2015. A área estudada foi considerada degradada após avaliação visual local, através de construções irregulares, ocorrendo a incidência de aterro com resíduos de construção 
e disposição incorreta de resíduos sólidos, o que provocou danos a vegetação em especial nas matas ciliares as margens do rio, com resultados de área vegetada em evolução decrescente nos anos 2006, 2011 e 2015, respectivamente de 61,65\%, $40,30 \%$ e $13,49 \%$, totalizando $86,51 \%$ de degradação da área de estudo, o que prejudica o escoamento de água em períodos de altas precipitações, gerando camadas impermeáveis em áreas de vales, o que o causa vulnerabilidade as áreas urbanas a riscos de inundações.

Palavras-Chave: Geoprocessamento, desvegetação, vulnerabilidade.

\section{Introdução}

A combinação de ações impactantes ao meio ambiente quanto a redução dos recursos naturais (Guimarães et al., 2009), sob a ação de impactos antrópicos negativos, geram a degradação ambiental. Isto, em muitos casos, ocorre devido a despreocupação humana com a sobrevivência das futuras gerações em função das necessidades atuais de infraestrutura urbana (Sucupira, 2006 apud Mota \& Valladares, 2011).

O desenvolvimento desordenado originado em 1950 no Brasil, por modernização e avanços tecnológicos na agricultura, provocou o êxodo rural (Martins, 2012), o qual provocou impactos ao meio ambiente, em decorrência das demandas básicas de moradia, necessidades de infraestrutura para as atividades produtivas e serviços públicos (Dias et al., 2008).

A definição da área de implantação de uma atividade comercial, industrial e residencial implica em observar os impactos ambientais relacionados ao uso do solo local, em adequação às leis de zoneamento e de uso e ocupação do solo (Dias et al., 2008) e de preservação de matas e corpos hídricos.

Atualmente, no Brasil, no município de Vitória de Santo Antão em Pernambuco, ocorre um acelerado crescimento econômico em função dos investimentos na área industrial, com elevação da população urbana e decrescimento da população rural (Melo, 2012). Porém, a incidência da pobreza no município apresenta-se elevada, sendo constatada através do Índice de Desenvolvimento Humano (IDH) de 0,4988 (Brasil, 2013), considerada por Melo (2012) como situação intolerável. Aliadas a esse fato estão as carências em infra-estrutura da polução, a exemplo de saneamento básico.

A ausência de serviços básicos no município de Vitória de Santo Antão compromete a qualidade da água dos rios que cortam a cidade, pelas ações antrópicas. A presença de lixo e resíduos de construção e demolição (RCD)às margens do rio, lançamento de esgoto doméstico, efluentes industriais clandestinos diretamente no corpo hídrico, e o carreamento de fertilizantes agrícolas e pesticidas, tanto no período chuvoso como na estiagem (Melo, 2012), geram a degradação com a poluição do rio e de suas áreas protegidas.

Segundo o Código Florestal, lei federal $\mathrm{n}^{\circ}$. 12.651, de 25 de maio de 2012, as Áreas de Preservação Permanentes (APP), como a vegetação natural situada ao longo dos rios ou qualquer curso d'água e as faixas marginais dos rios, de outros cursos d'água e dos locais de declives, devem ser protegidas e recuperadas (Brasil, 2012; Dias et al., 2008).

O principal rio do município de Vitória de Santo Antão é o Tapacurá, constituindo 38,6\% da área de drenagem nessa cidade, cortando outros cinco municípios (Melo, 2012). Esse rio possui $76,2 \mathrm{~km}$ de extensão, área de drenagem com cerca de $472 \mathrm{~km}^{2}$, desde a sua nascente, no município de Gravatá, até a sua desembocadura, no município de São Lourenço da Mata (Silva et al., 2010; Santos et al., 2014). Sua vazão média é de $6,1 \mathrm{~m}^{3} \cdot \mathrm{s}^{-1}$ e vazão máxima de $50,7 \mathrm{~m}^{3} \cdot \mathrm{s}^{-1}$, em períodos chuvosos (Melo, 2012), provocando inundações em área de altitudes baixas.

O objetivo deste estudo consistiu em identificar a degradação ambiental por ações antrópicas em área urbana, às margens do rio Tapacurá, no município de Vitória de Santo Antão$\mathrm{PE}$, utilizando técnicas de geoprocessamento de dados.

\section{Material e Métodos}

O estudo foi desenvolvido em uma área com visível presença de aterros com Resíduos de Construção e Demolição (RCD) às margens do rio Tapacurá, em 54,48 ha, em um trecho de 943 m, delimitado pelas pontes do Galucho (P1) e do Dique (P2), principais vias de acesso aos bairros do Maranhão e Ferreiros, no município de Vitória de Santo Antão, na Zona da Mata do estado de Pernambuco, Brasil (Figura 1), durante os meses de junho e julho de 2016. 


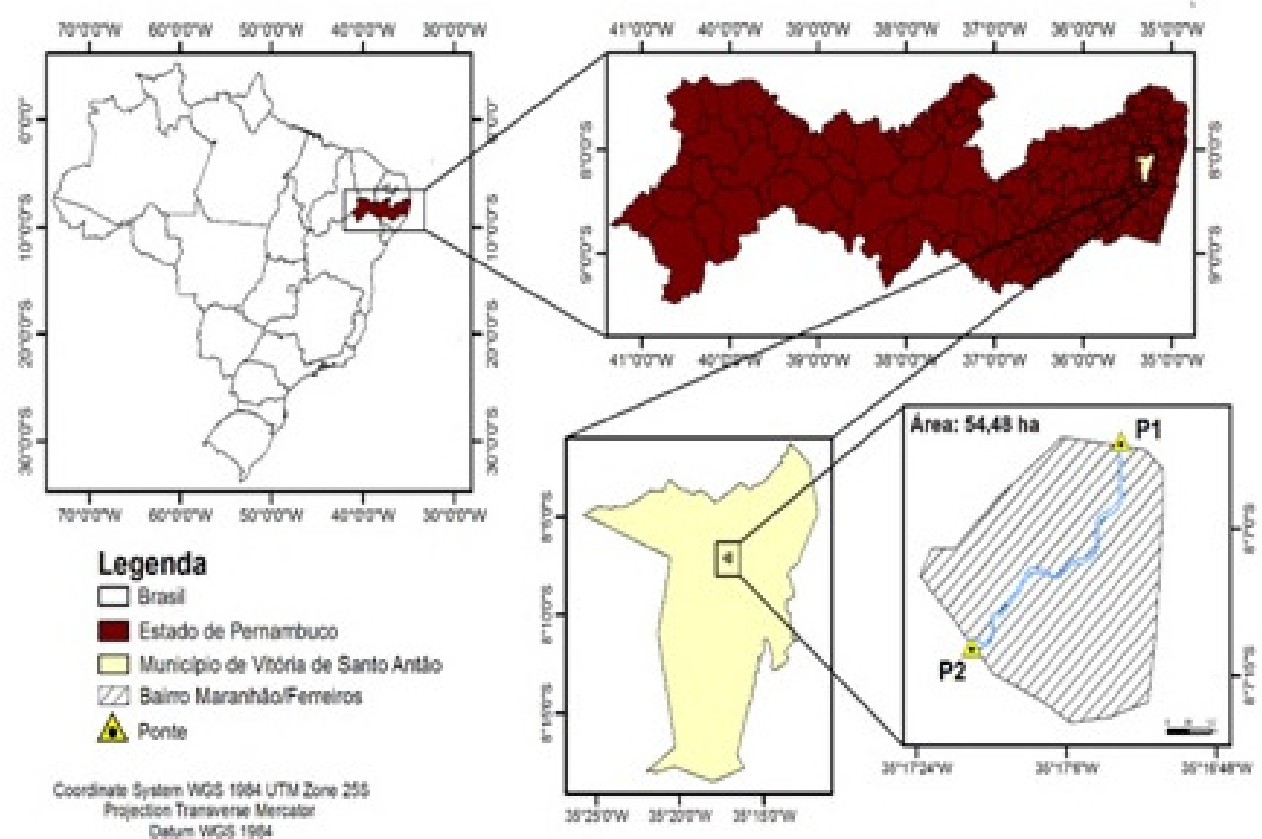

Figura 1. Mapa de localização da área de estudo, no município de Vitória de Santo Antão, na Zona da Mata do estado de Pernambuco.

\section{Resultados}

O município de Vitória de Santo Antão ocupa $371,796 \mathrm{~km}^{2}$ e representa $0,35 \%$ do estado de Pernambuco, com uma população de 129.974 habitantes, estando 113.429 desta na zona urbana e 16.545 na zona rural. A sede do município tem uma altitude aproximada de $156 \mathrm{~m}$ e localização nas coordenadas geográficas de $08^{\circ} 07^{\prime} 05^{\prime}$ ' de latitude sul e $35^{\circ} 17^{\prime} 29^{\prime \prime}$ ' de longitude oeste, distando 45,1 $\mathrm{km}$ da capital, Recife, cujo acesso é feito pela BR232 (IBGE, 2010; Azevedo et al., 2015).

Foi realizado um levantamento de informações junto à Agência de Meio Ambiente de
Vitória de Santo Antão (AMAVISA), em junho de 2016, com a finalidade de serem identificadas as leis e as obrigações governamentais e da sociedade.

Realizaram-se visitas do campo nos meses de junho e julho de 2016, atendendo as extensões demarcadas pela área estudada, através das coordenadas P1 $\left(8^{\circ} 6^{\prime} 51\right.$ "S e $\left.35^{\circ} 16^{\prime} 59^{\prime \prime O}\right)$ a P2 $\left(8^{\circ} 7^{\prime} 12^{\prime \prime} \mathrm{S}\right.$ e $\left.35^{\circ} 17^{\prime} 38^{\prime \prime} \mathrm{O}\right)$. Foi realizada coleta de informações, incluindo caracterização visual da área, como agrupamento de fotografias com as coordenadas georeferenciadas pelo equipamento Etrex Vista-Garmin (Figura 2).

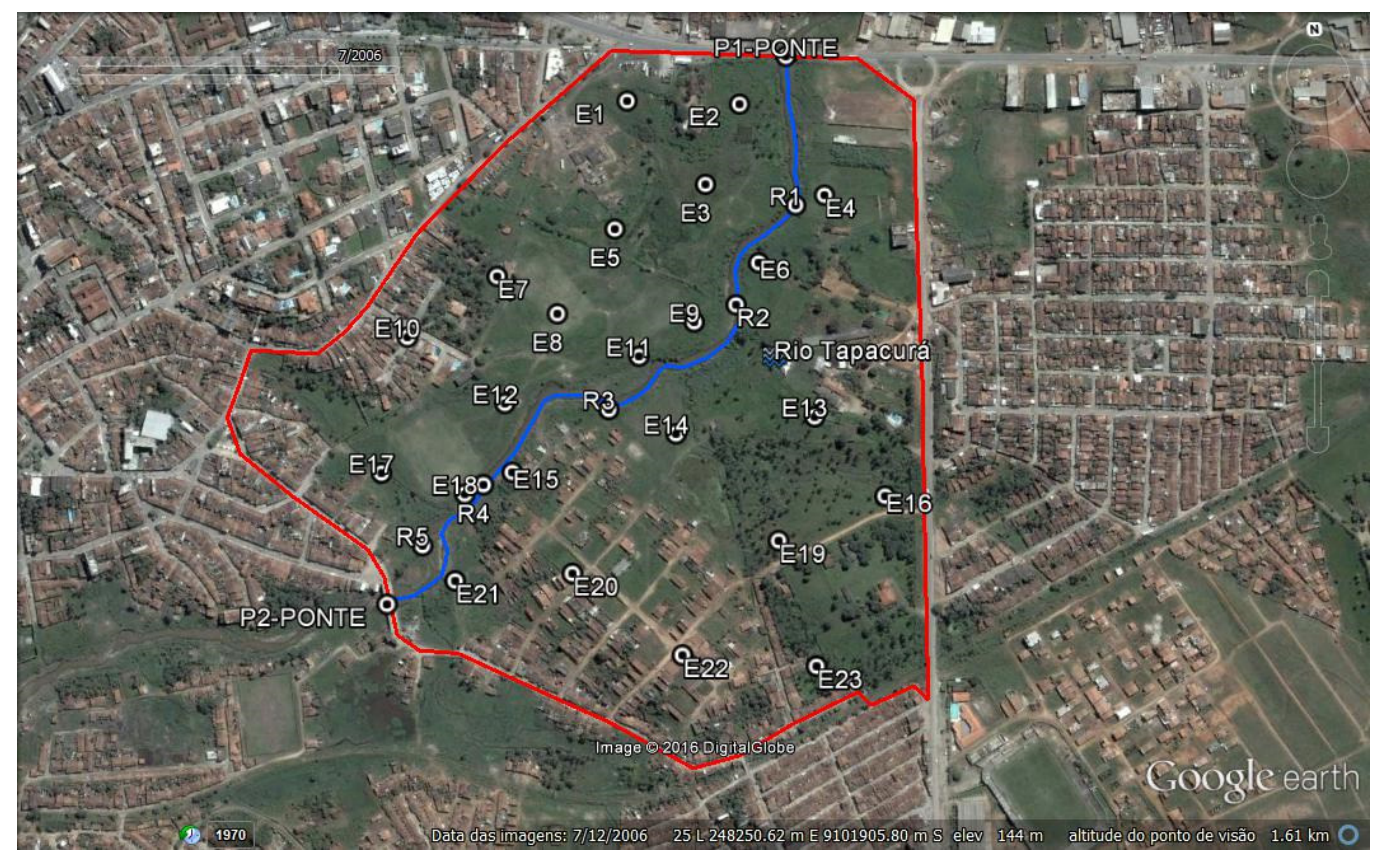

Figura 2. Mapa do Google Earth Pro, em julho de 2006, com delimitação da área de estudo e sinalização do rio Tapacurá. Fonte: Adaptada do Google Earth Pro (2016). 
Foi utilizado o Google Earth Pro para identificar pontos de análises de áreas vegetadas nos mapas nos meses de julho de 2006, junho de 2011 e novembro de 2015 , com a finalidade de verificar a evolução da degradação por meio do comprometimento da superfície vegetada. Em seguida, foram comparados os mapas, gerando-se a representação gráfica e calculada para a área não vegetada, como índice de degradação ambiental e sua evolução.

O índice de área não vegetada (IANV) foi calculado aplicando a seguinte fórmula:

$\mathrm{IANV}=\frac{\text { Quant total de área vegetada no ano estudado }}{\text { Quantidade total estudada }} \times 100 \%$
Foram considerados como níveis críticos de degradação, as áreas não vegetadas ocupando acima de $75 \%$, níveis altos entre $50 \%$ e $75 \%$, níveis médios entre $25 \%$ a $50 \%$ e níveis baixos quando inferiores a $25 \%$.

\section{Resultados}

Comparando as áreas degradadas, verificou-se uma evolução na desvegetação ao longo dos anos, comprometendo a Área de Preservação Permanente (APP). Essa evolução foi observada devido a ocupação urbana próxima às margens do rio (Figuras 3-5).

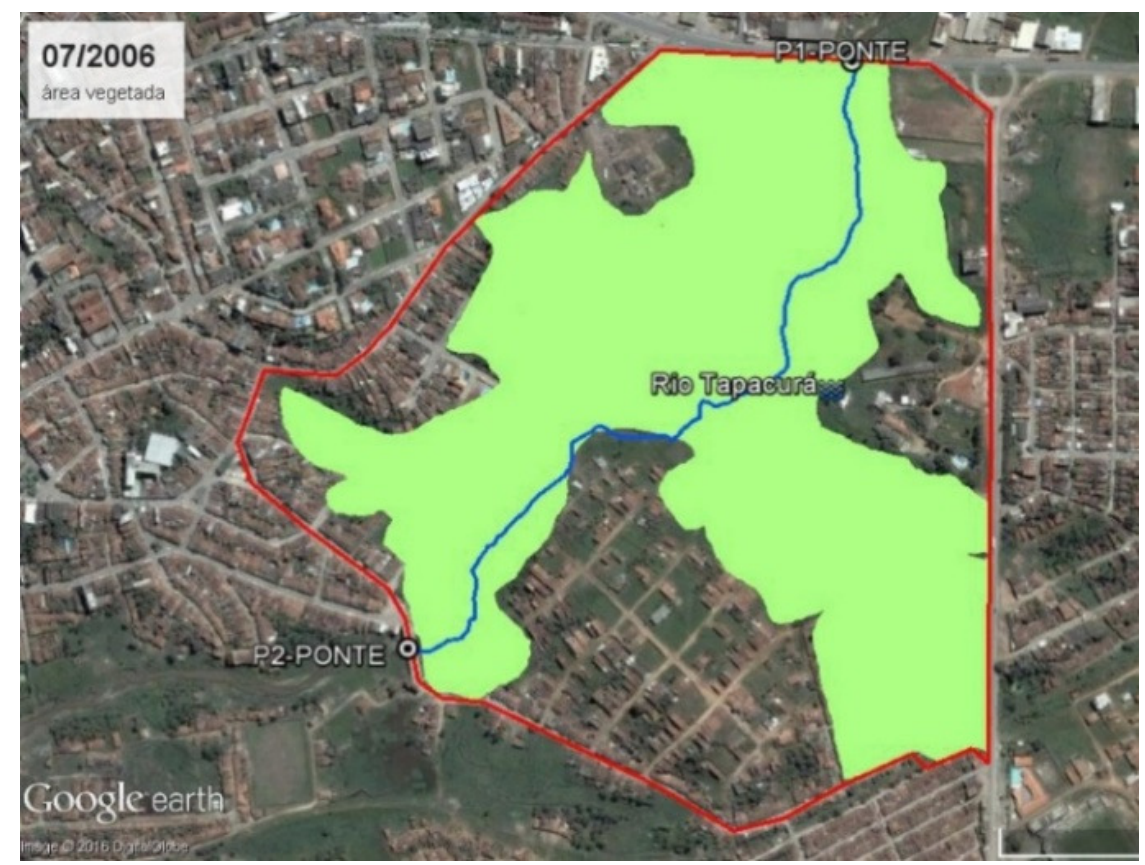

Figura 3. Área vegetada em julho de 2006, com área de 33,59ha, representando 61,65\% da área estudada.

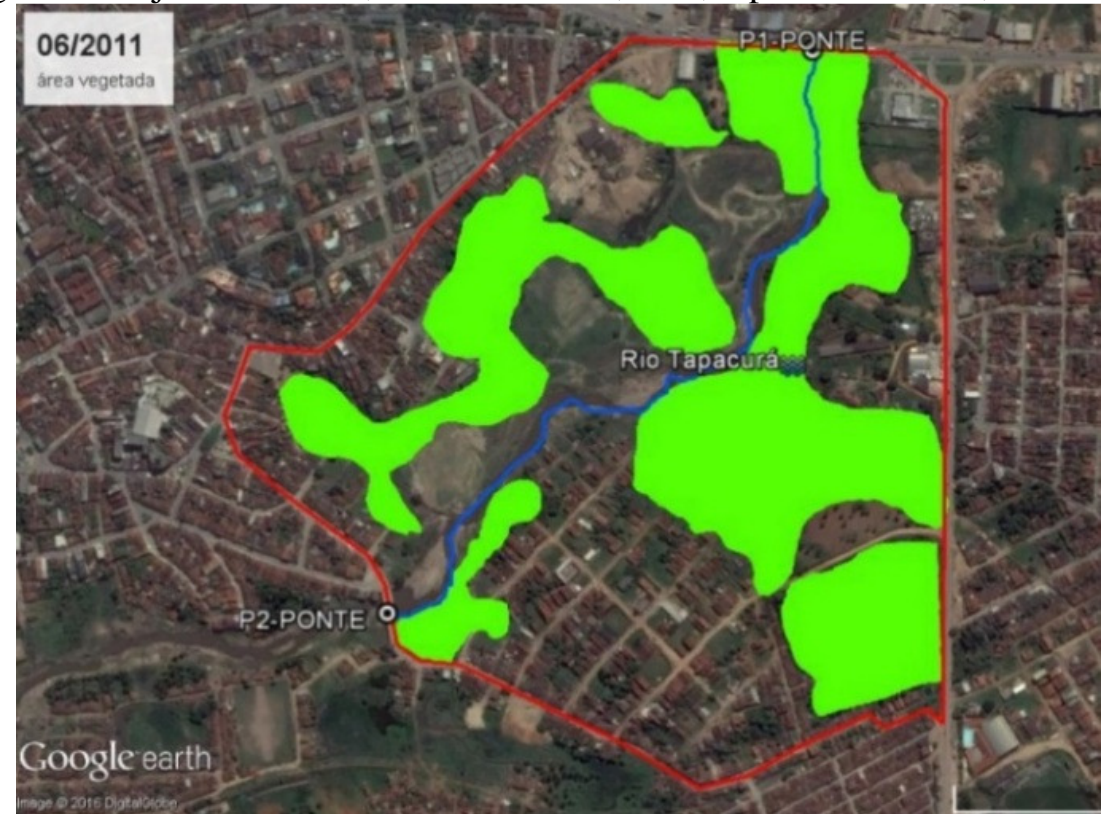

Figura 4. Área vegetada em junho de 2011, com área de 21,96ha, com representação de 40,30\% da área estudada. 


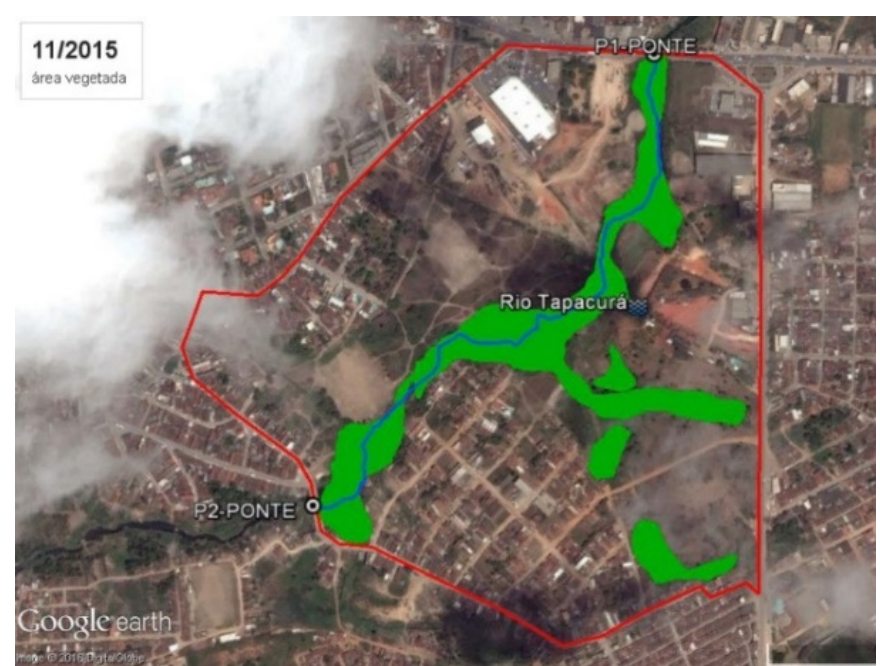

Figura 5. Área vegetada em novembro de 2015, com área de 7,35 ha, representando 13,49\% da área estudada.

Com a evolução ao longo dos anos estudados, é possível observar uma evolução que indica uma degradação acentuada do ambiente (Figura 6).

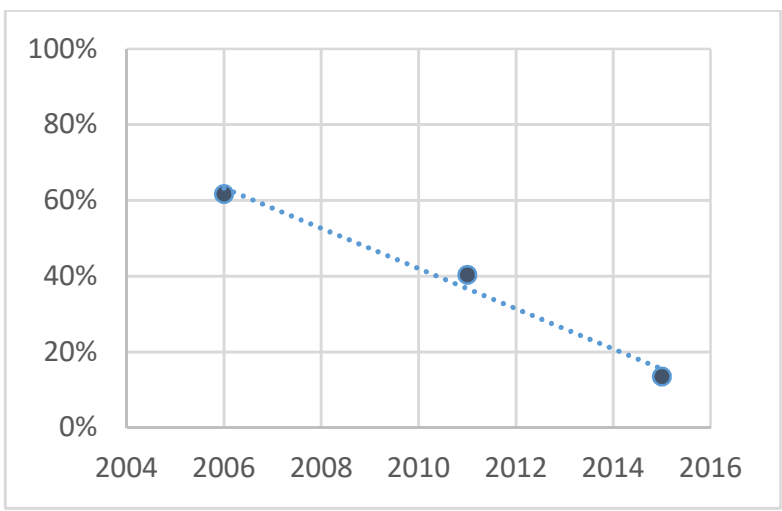

Figura 6. Comprometimento da vegetação na área em estudo em 2006, 2011 e 2015.
Como resultado das vistas ao campo em junho e julho de 2016 foi identificado resíduos domésticos, Resíduos de Construção e Demolição (RCD) e de outras atividades comerciais (Figuras 7-9).

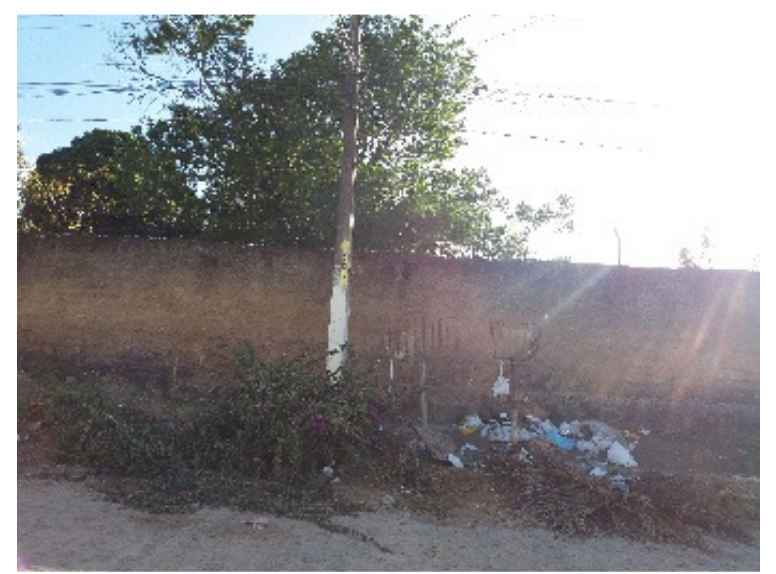

Figura 7. Disposição inadequada de resíduos domésticos, imagem obtida em junho/2016.

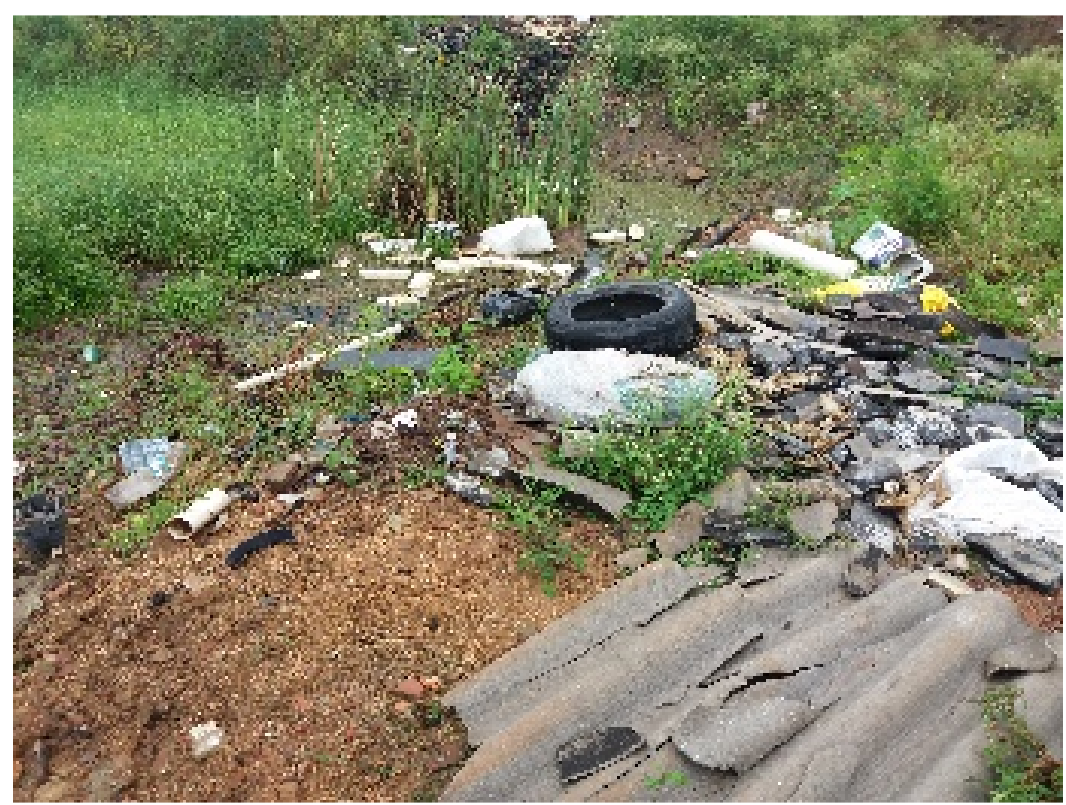

Figura 8. Disposição inadequada de resíduos de construção e outros, imagem obtida em junho/2016. 


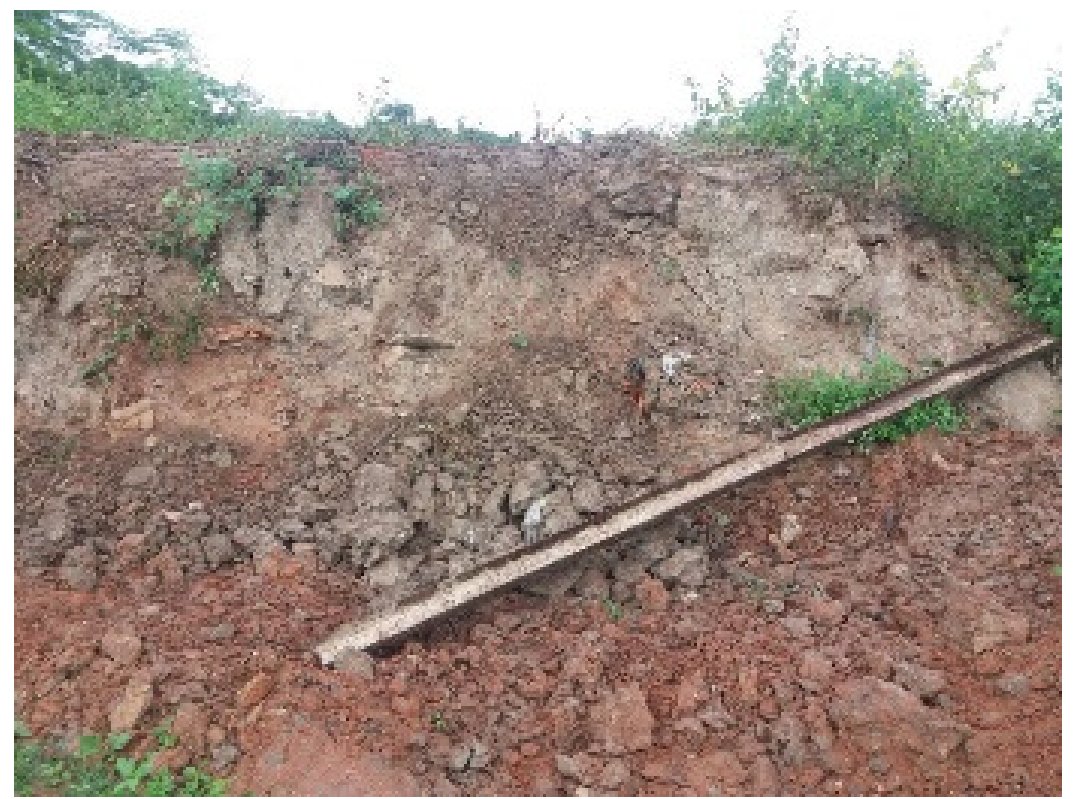

Figura 9. Aterro de resíduos de construção, imagem obtida em junho/2016.

As incidências de aterros com resíduos de construção civil são evidentes ao longo da área estudada. Foi observado aterro às margens do rio, com $1,5 \mathrm{~m}$ de horizonte de aterro, além de disposição de RCD às margens do rio Tapacurá no trecho estudado. Considerado um grande problema para o meio ambiente, os RCD representam de 50\% a $60 \%$ dos resíduos sólidos urbanos produzidos nas grandes cidades (Gusmão, 2008 apud Siqueira, 2015).

Os resíduos da construção civil não podem ser dispostos em aterros de resíduos sólidos urbanos, em áreas de bota fora, em encostas, em corpos d'água, em lotes vagos e em áreas protegidas por lei (CONAMA, 2002), tais como APP e reserva ecológica (DIAS et al., 2008). A presença de $\mathrm{RCD}$, com uso para aterro em área marginal, provoca o desmatamento das matas ciliares, dificultando o funcionamento dos canais de drenagem natural do solo.

Como alternativa para corrigir ou atenuar tal problema, poder-se-ia realizar a reciclagem dos RCD, minimizando a degradação ambiental por reduzir a disposição inadequada no ambiente (Carmo, Maia \& César, 2012; Siqueira, 2015).

\section{Discussão}

Analisando as leis municipais ambientais, observou-se que o Plano Diretor do município de Vitória de Santo Antão, lei municipal 3.199 de 27 de novembro de 2006, no Plano de Uso e Ocupação do Solo, lei municipal de 24 de novembro de 2008, que trata da Lei Orgânica, como também o Código de Meio Ambiente, lei 3.768 de 18 de fevereiro de 2013, não contemplam as delimitações das APPs da cidade. Porém, a legislação municipal descreve uma APP como área de ocupação em fundos de vales, áreas sujeitas a inundações, das áreas de declividade acentuadas, nas cabeceiras de drenagem e das matas e áreas verdes significativas (Vitória de Santo Antão, 2006, 2008, 2013).

A representação gráfica da evolução do comprometimento da área vegetada, segundo Boratto \& Gomide (2013), se constitui em um dos meios para se verificar a degradação do solo, usando o acompanhamento do índice de área vegetada.

Foi observado um índice de degradação, da área em estudo, de $86,51 \%$ do total, sendo considerado um alto grau de degradação, demonstrando uma tendência. No estudo de Salamane et al. (2011) foi verificado que o índice de degradação correspondeu a apenas $26 \%$ do Rio Guandu-RJ, considerado um baixo grau de degradação. No caso em estudo, a degradação foi considerada crítica, com índice acima de $75 \%$, pela definição na metodologia aplicada.

A degradação dos solos como consequência do corte de vegetação, como ocorre em áreas edificadas, aliadas às exposições do solo, fragiliza o livre escoamento das águas, sendo fator responsável por inundações e alagamentos (Rodrigues \& Listo, 2016).

A presença de área edificada, na área em estudo, resulta na degradação pela ocupação irregular e por fatores de ocupação indevida das margens do rio, nas áreas urbanas com moradias precárias. Some-se a este fato, a falta de sistema de gerenciamento de resíduos sólidos e saneamento eficazes, contribuindo com a cultura de jogar lixo e conduzir esgotos domésticos direto ao rio, o que gera poluição e contaminação indiscriminada do corpo hídrico (Azevedo et al., 2015). 
$\mathrm{O}$ crescimento do município em estudo deu-se pela necessidade de utilização de áreas próximas ao centro comercial, não observadas as áreas com necessidade de preservação, sendo elas ocupadas por moradias e comércios, ocasionando a ausência de recursos, como saneamento básico e a não fiscalização das disposições dos resíduos sólidos.

Em seu estudo, Azevedo et al. (2015) observaram o descaso com a disposição final para os resíduos utilizados pela própria população local, no município estudado; na última grande enchente da cidade, as moradias das margens do rio Tapacurá foram severamente prejudicadas, provocando alguns óbitos.

\section{Conclusão}

A área estudada foi considerada degradada por ações antrópicas, através do elevado índice de desvegetação calculado para os meses de julho de 2006, junho de 2011 e novembro de 2015, mostrando uma evolução da degradação através do comprometimento da superfície vegetada, confirmada pela ocorrência de aterros irregulares com resíduos de construção e disposição incorreta de resíduos sólidos.

A degradação acentuada de solo prejudica o escoamento da água em períodos de altas precipitações, gerando camadas impermeáveis em áreas de vales, promovendo vulnerabilidade às áreas urbanas com riscos de inundações.

\section{Agradecimentos}

Os autores agradecem ao Grupo de Pesquisa Centro de Inovação Tecnológica Aplicada aos Recursos Naturais (Citar).

\section{Referências}

AZEVEDO, D. S.; SILVA, H. P.; FABISAK, M. M.; CALDAS, K. F. R. 2015. Disposição de resíduos sólidos em áreas ciliares do rio Tapacurá no município de Vitória de Santo Antão, PE, Resíduos sólidos, Tecnologias limpas e boas práticas, In: EL-DEIR, S. G.; GUIMARÃES, E. DA S. (Org.). Resíduos sólidos: tecnologias limpas e boas práticas. 1ed. Recife: UFRPE, pp. 241-249.

BRASIL. Atlas de desenvolvimento humano do Brasil. 2013. Disponível em: http://www.atlasbrasil.org.br/2013/pt/home/ Acesso em: 18 de ago. 2016.

BRASIL. 2012. Presidência da República. Lei federal n. 12.651. Dispõe sobre a proteção da vegetação nativa, de 25 de maio de 2012. Brasília, DF. Disponível em: http://www.planalto.gov.br/ccivil_03/_ato2011- 2014/2012/lei/112651.htm. Acesso em: 18 jul. 2016.

BORATTO, I. M. P.; GOMIDE, R. L. 2013. Aplicação dos índices de vegetação NDVI, SAVI e IAF na caracterização da cobertura vegetativa da região Norte de Minas Gerais. In: XVI Simpósio Brasileiro de Sensoriamento Remoto, Foz do Iguaçu, PR, Brasil. INPE.

CARMO, D. S.; MAIA, N. S.; CÉSAR, C. G. 2012. Avaliação da tipologia dos resíduos de construção civil entregues nas usinas de beneficiamento de Belo Horizonte. Engenharia Sanitária e Ambiental, v. 17, n. 2, p. 187-192.

CONAMA. Conselho Nacional de Meio Ambiente. Resolução no 307, 05 de julho de 2002. Estabelece diretrizes, critérios e procedimentos para a gestão dos resíduos da construção civil. Disponível em: http://www.mma.gov.br/port/conama/legiabre.cfm ?codlegi=307. Acesso em: 30/06/2015.

DIAS, M. DO C. O.; PEREIRA, M. C. B.; DIAS, P. L. F.; VIRGÍliO, J. F. 2008. Manual de impactos ambientais. $2^{\mathrm{a}}$ edição, Fortaleza, CE, Banco do Nordeste. 322p.

IBGE. 2010. Instituto Brasileiro de Geografia e Estatística (2010). Censo Populacional 2010. Rio de Janeiro, RJ. IBGE, 2010. Disponível em: http://www.ibge.gov.br/home/geociencias/geograf ia/geografia_urbana/arranjos_populacionais/tabela s.shtm. Acesso em: 05 julho de 2016.

GUIMARÃES, A. E. N.; VINICIUS, E.; BATISTA, P. G.; SOUZA, Z. 2009. Análise para recuperação de uma área degradada, na micro bacia do Ribeirão Taquaruçu, PALMAS, TO, Faculdade Católica do Tocantis. nov/2009.

MARTINS, K. 2012. Expansão urbana desordenada e os riscos ambientais e a saúde humana - Estudo de caso brasileiro. (Monografia para Gestão Ambiental), Universidade de Brasília, DF. 65p.

MELO, S. C. 2012. Análise quali-quantitativa no rio Tapacurá no município de Vitória de Santo Antão-PE. (Monografia para Engenharia Ambiental), Universidade Maurício de Nassau, Recife.

MOTA, L. H. DA S. DE O.; VALLADARES, G. S. 2011. Vulnerabilidade à degradação dos solos da Bacia do Acaraú, Ceará, Revista Ciência Agronômica, v. 42, n. 1, p. 39-50. 
RODRIGUES, F. S.; LISTO, F. de L. R. 2016. Mapeamento de áreas de risco a escorregamentos e inundações em áreas marginais a rodovias na Região Metropolitana de São Paulo. Engenharia Sanitária e Ambiental, v.21, n.4, p.765-775.

SALAMENE, S.; FRANCELINO, M. R.; VALCARCEL, R.; LANI, J. L.; SÁ, M. M. F. 2011. Estratificação e Caracterização Ambiental da Área de Preservação Permanente do Rio Guandu/RJ. Revista Árvore, Viçosa, v. 35, n. 2, p. 221-231.

SANTOS, J. Y. G.; SILVA, R. M.; MONTENEGRO, S. M. G. L.; SANTOS, C. A. G. 2014. Aplicação do modelo SWAT para a estimativa da produção de sedimentos na bacia do rio Tapacurá, Pernambuco. In: XI Encontro Nacional de Engenharia de Sedimentos. João Pessoa, PB.

SILVA, R. M.; SILVA, L. P.; MONTENEGRO, S. M. G. L.; SANTOS, C. A. G. 2010. Análise da variabilidade espaço-temporal e identificação do padrão da precipitação na bacia do rio Tapacurá, Pernambuco. Sociedade \& Natureza, v. 22, p. 357372.

SIQUEIRA, S. L. A. DE. 2015. Gerenciamento de resíduos na construção civil - Um estudo de caso (monografia para Engenharia Civil), Universidade Católica de Pernambuco, Recife.

VITORIA DE SANTO ANTÃO. 2006. Prefeitura Municipal. Lei municipal n. 3199, de 27 de novembro de 2006. Plano diretor do município de Vitória de Santo Antão-PE.

VITORIA DE SANTO ANTÃO. 2013. Prefeitura Municipal. Lei municipal n. 3.768, de 18 de fevereiro de 2013. Código de Defesa do Meio Ambiente.

VITORIA DE SANTO ANTÃO. 2008. Prefeitura Municipal. Lei orgânica do município de Vitória de Santo Antão-PE, de 14 de novembro de 2008. 